\title{
A política de avaliação da produtividade acadêmica brasileira sob a ótica dos pesquisadores: uma meta-síntese
}

\author{
The Brazilian's academic productivity evaluation \\ policy from the researchers' perspective: a meta-synthesis
}

Luana Silvy de Lorenzi Tezza Magnin ${ }^{1}$

Adriana Takahashi ${ }^{2}$

Resumo: A meta de publicar com frequência em revistas de excelência tem configurado a jornada exaustiva de muitos docentes. Esta meta-síntese tem como objetivo verificar como os pesquisadores brasileiros têm estudado o posicionamento de seus pares diante da política de avaliação da produtividade científica no país formulada pela CAPES e CNPQ. Esses órgãos adotam critérios de produtividade que balizam a avaliação dos programas de pós-graduação e de seus docentes. Foram localizados 46 artigos científicos, dos quais 4 foram utilizados para a meta-síntese. Os critérios de seleção e análise adotados partem da filosofia de linguagem de Bakhtin: criticidade, plurilinguismo, posicionamento ideológico, qualidade dos insights e contextualização sócio-histórica. Mesmo os poucos estudos que atenderam aos critérios citados priorizam metodologias que amparam-se na lógica de mensuração quantitativa, havendo insuficiente apropriação de aspectos históricos e das vozes, nas análises. Verificou-se que a política de avaliação não apenas avalia, mas fortalece e induz determinadas práticas de pesquisa. Ao não se problematizar o contexto e as vozes, corre-se o risco de se adotar posicionamentos funcionalistas, que legitimam enunciados já em evidência, naturalizando-se a realidade e comprometendo-se a concepção do sujeito como agente de transformação. Conclui-se que estudos que possuem como objeto as políticas de avaliação devem considerar a construção dos modos de subjetividade do pesquisador. Há aspectos pouco esclarecidos na literatura no que se refere à maneira como os critérios de avaliação interferem nas formas de subjetivação do pesquisador, e em como ele organiza e significa o seu fazer e a si mesmo.

Palavras-chave: Avaliação. Bakhtin. Produtividade. 
Abstract: The goal of frequent publishing in journals of excellence has resulted in exhaustive journeys of many teachers. This meta-synthesis aims to verify how the Brazilian researchers have studied the positioning of their peers, considering the scientific productivity's evaluation policy in the country formulated by CAPES and CNPQ. Those institutions adopt productivity criteria that guide the evaluation of postgraduate programs and their teachers. A total of 46 scientific papers were found, of which 4 were used for the meta-synthesis. The criteria of selection and analysis adopted were based on Bakhtin's language philosophy: criticality, plurilingualism, ideological positioning, quality of insights and sociohistorical contextualization. Even the few studies that met the above criteria prioritize methodologies that are based on quantitative measurement logic, with insufficient appropriation of historical aspects and voices in the analyzes. It was verified that the evaluation policy not only evaluates, but strengthens and induces certain research practices. By not problematizing the context and the voices, one runs the risk of adopting functionalist positions, which legitimize statements already in evidence, naturalizing reality and failing to recognize the individuals as transformation agents. We conclude that studies that focus on evaluation policies should consider the construction of the researcher's modes of subjectivity. There is not enough clarity in the literature about how does evaluation criteria interfere on individual's subjectivity and on how does one organizes and gives meaning to it's work and himself.

Keywords: Evaluation. Bakhtin. Productivity.

${ }^{1}$ Instituto Carlos Chagas | Programa de Pós-Graduação | Cidade| XX | Brasil. Contato: luanasilvy@hotmail.com. ORCID: https://orcid.org/0000-0002-3330-9835

${ }^{2}$ Universidade Federal do Paraná | Programa de Pós-Graduação | Cidade| XX | Brasil. Contato: adrianarwt@terra.com.br. ORCID: http://orcid.org/0000-0002-4738-5273

- Recebido em: 17 de setembro de 2019

- Aprovado em: 13 de junho de 2021

DOI: http://dx.doi.org/10.1590/S1414-40772021000300006

Este é um artigo publicado em acesso aberto sob uma licença Creative Commons https://creativecommons.org/licenses/by-nc/4.0/ 


\section{Introdução}

O cenário de pesquisa no Brasil alterou-se significativamente nos últimos anos. Dentre as principais mudanças, destaca-se a adoção de critérios objetivos para a avaliação da produção científica do país. As estatísticas são otimistas: na última década, o número de publicações por pesquisador no país aumentou significativamente, passando de $0,56 \%$ a uma participação de $1,54 \%$ da base mundial. O número de publicações dobrou no período, e o Brasil é atualmente o $9^{\circ}$ país que mais publica no ranking internacional (GOLDANI et al., 2010).

Segundo Lawrence (2003), publicar em um jornal bem qualificado significa "entrar para a elite científica". Ao mesmo tempo, o pesquisador brasileiro enfrenta um ambiente extremamente competitivo, por vezes hostil, para obter recursos de pesquisa e precisa continuamente provar sua capacidade. Muitos pesquisadores são descredenciados de programas de pós-graduação, ao mesmo tempo em que são submetidos a novas formas de avaliação individual, pautada por número de publicações e fator de impacto. A reputação científica tem sido baseada em métricas científicas e assume-se que o impacto da revista garante a importância das descobertas. O financiamento de pesquisas é bastante restrito, sendo que a grande maior parte dos investimentos em pesquisa no país concentram-se nas universidades públicas, o que incrementa a competitividade interna (MEIS et al., 2003; PEDRINI, 2005; GOLDANI et al., 2010).

Embora seja majoritário o entendimento de que as políticas de avaliação possuem um papel bastante relevante, os critérios de avaliação adotados têm gerado intensos debates acadêmicos, por divergência de posicionamentos ideológicos e concepções sobre qual é, afinal, o papel da universidade em um contexto neoliberal que tem gerado extrema exclusão e minorias (do ponto de vista social) bastante numerosas (sob a perspectiva quantitativa).

Verificou-se que, embora haja inúmeros trabalhos críticos e de revisão teórica publicados sobre essa temática, são poucos os estudos de caso que trataram especificamente do posicionamento do pesquisador frente à política de avaliação adotada no país. Nesse sentido, é objetivo dessa meta-síntese verificar como os pesquisadores brasileiros tem estudado o posicionamento de seus pares diante da política de avaliação da produtividade científica no país formulada pela CAPES e CNPQ.

Este artigo divide-se em cinco seções. A primeira relata a lacuna teórica acerca da temática; a segunda apresenta o referencial teórico; a terceira delimita os procedimentos metodológicos adotados e estrutura as fases da pesquisa; a quarta realiza uma discussão a partir dos artigos selecionados acerca da temática, conforme os procedimentos metodológicos delineados; e a quinta seção apresenta as principais conclusões e achados teóricos da pesquisa. 


\section{Políticas de avaliação, ideologia e modos de objetivação-subjetivação}

O parecer CFE n 977/65 (BRASIL, 1965), emitido pelo Conselho Federal de Educação e redigido por Newton Sucupira, foi um importante marco regulador da pós-graduação sistemática no Brasil. Por meio dele, reconheceu-se que os cursos de pós-graduação ofertados no País eram muito restritos, e que seria necessária uma política de indução, para que os pesquisadores brasileiros não tivessem que, sistematicamente, realizar sua formação avançada no exterior, por falta de opção no País. A necessidade de regulamentação é justificada, no documento, por três motivos:

1) formar professorado competente que possa atender à expansão quantitativa do nosso ensino superior garantindo, ao mesmo tempo, a elevação dos atuais níveis de qualidade; 2) estimular o desenvolvimento da pesquisa científica por meio da preparação adequada de pesquisadores; 3 ) assegurar o treinamento eficaz de técnicos e trabalhadores intelectuais do mais alto padrão para fazer face às necessidades do desenvolvimento nacional em todos os setores (BRASIL, 1965).

Existe grande pluralidade de critérios e indicadores de avaliação, mensuração e qualificação de trabalhos e desempenho individual disponíveis na literatura. A necessidade de avaliação para os mais diversos tipos de trabalho, como já enunciado, é entendimento majoritário. Mas, quais os efeitos de determinada política avaliativa adotada - sobre os indivíduos, os grupos de pesquisa, as universidades, o país?

O processo avaliativo não afere apenas o resultado final de um trabalho de pesquisa, mas induz inclusive o tipo de pesquisa e publicação, a forma de escrita, o tempo de submissão, ou seja, induz práticas específicas. Portanto, cabe refletir que a prática avaliativa adotada não é mera mensuração de resultados, mas balizadora do próprio processo de trabalho do pesquisador (HANAFI, 2011).

Conforme aponta Faria (2017), as práticas de avaliação de desempenho são formas de controle do trabalhador, do processo e resultados do trabalho. A mesma reflexão pode ser feita em relação ao pesquisador: na medida em que são estipulados critérios de avaliação, o pesquisador tende a dar ênfase para a execução das tarefas que serão efetivamente avaliadas (publicação), em detrimento de outras tarefas menos valorizadas no ambiente acadêmico, como o ensino e extensão.

No mesmo sentido, segundo Machado e Pan (2012), quando as políticas públicas incidem sobre a educação, atuam também sobre os modos de subjetivação de uma sociedade, já que se configuram como orientadoras dos processos educacionais. Portanto, a política de avaliação dos docentes-pesquisadores não é neutra e arbitrária, comprometida apenas com objetivos definidos e explícitos, mas reflete e refrata o posicionamento ideológico de seus idealizadores, e é produtora de modos específicos e determinados de ser e existir enquanto 
pesquisador. Esses modos de subjetivação prescritos no texto de uma política pública atuam na forma como o trabalhador significa sua existência - como age, posiciona-se, manifesta-se e/ou se silencia -, dentro e fora das universidades.

Segundo Simões (2004), a adoção do critério de publicação internacional, por um lado, evita o "compadrio corporativo"; por outro, adotado como único critério, cria distorções. A autora defende que teorias ditas "universais" repercutem na definição das políticas educacionais brasileiras e com isso [...] "visa-se atender a normas ditadas por organismos internacionais, em detrimento das necessidades e dos desejos expressos por segmentos acadêmicos e sociais brasileiros" (p. 125-126). A autora reflete sobre "que ensino e que pesquisa acontecem (e especialmente deixam de acontecer) enquanto tentamos nos "ajustar" ao modelo de avaliação vigente".

\subsection{Produção para que(m)? Uma ciência posicionada}

Diversos autores (NUNES; NUNES, 2013) defendem que o pesquisador está cada vez mais submetido às leis do mercado. Surgem termos como "produtivismo acadêmico", o artigo como "mercadoria acadêmica", que têm demonstrado facetas dessa aproximação. Segundo Nunes e Nunes (2013), o aumento da produtividade do trabalho é uma imposição feita às empresas privadas, mas também às instituições públicas.

Torna-se necessário ponderar seus efeitos: ao mesmo tempo em que o aumento de produtividade possa trazer avanços científicos, e não se nega a contribuição resultante de esforços dos mais variados pesquisadores, há consequências negativas nos diversos níveis: institucional, organizacional e individual.

Segundo Tragtenberg (1990), em nome do "atendimento à comunidade" e "serviço público", a universidade tende cada vez mais à adaptação indiscriminada a quaisquer pesquisas a serviço dos interesses econômicos hegemônicos. Tragtenberg (1990) aborda criticamente a questão da responsabilidade social do intelectual acadêmico, que, enquanto foca cegamente no cumprimento de critérios de publicação e produção, muitas vezes deixa de enxergar-se enquanto importante fomentador da pesquisa que poderia, de fato, transformar a realidade social. Segundo o autor, "A delinquência acadêmica se caracteriza pela existência de estruturas de ensino onde os meios (técnicas) se tornam os fins, os fins formativos são esquecidos".

Para Bertonha (2009, p. 520), “a 'ditadura numérica' tende a inibir a produção de material para um público mais amplo, faz muita gente desvalorizar a atividade didática e gera a produção de muita coisa inútil". Esses “produtos" devem oferecer uma “solução 'just in time' de problemas pontuais que afetam os potenciais consumidores" (BERTONHA, 2009, p. 520), 
que podem ser os "estudantes-clientes", no caso da docência. Para Ibarra-Colado (2003 apud BERNARDO 2014),

os pesquisadores perderam o controle do conteúdo e da organização do trabalho e, assim, perderam sua condição de artesãos do saber para conformarem-se paulatinamente em engrenagens de alguma das grandes maquinarias que integram as novas formas de produção do conhecimento. (BERNARDO, 2014, p. 1062).

Segundo Bernardo (2014), a política de produção afeta as atividades de pesquisa, sendo que

a pós-graduação e, consequentemente, a pesquisa, tornaram-se o principal foco de avaliação do trabalho docente na universidade brasileira, sendo esta fundamentada em dados quantitativos de produtividade, especialmente, no número de publicações, número de orientações e horas-aula e prazos de conclusão de mestrados e doutorados.

Nesse mesmo sentido, Castiel et al. (2007) apontam que:

\begin{abstract}
a imagem predominante do autor de artigos científicos está deixando de ser a do 'gênio romântico', que dedica sua inteligência e capacidade de análise para propor formas de inquirir mistérios do mundo para benefício humano [...] Agora, grande parte dos autores inclui aqueles que atuam como "empregados" de empresas, funcionários que se dedicam a seguir a rotina de protocolos estabelecidos em propostas de investigação aceitas pelas agências financiadoras e consagradas pela comunidade científica ( $\mathrm{p}$. 3046).
\end{abstract}

Burian Jr. (2009 apud BERNARDO, 2014), destaca as distorções desse modelo. A primeira seria que "não se publica para o artigo ser lido, publica-se para melhorar o currículo do autor" (p. 17). A segunda seria o encorajamento de artigos superficiais, apressados e/ou repetições de textos com pequenas alterações. Outra distorção diz respeito à autoria múltipla, que passa a ser comum, mesmo que, muitas vezes, algum dos autores tenha uma parcela ínfima de participação na produção do trabalho.

Chauí (2003) questiona como foi possível passar da ideia da universidade como instituição social à sua definição como organização prestadora de serviços. Segundo a autora, as novas formas de financiamento das pesquisas e a submissão delas às exigências do próprio capital tem transformado a universidade numa organização ou numa entidade operacional (p. 7). É neste cenário que este trabalho se insere, cuja investigação foi realizada conforme delineamento a seguir descrito.

\title{
3 Desenho de pesquisa
}

De acordo com Hoon (2013), após a clara definição da pergunta de pesquisa, devem ser criteriosamente selecionados os artigos a serem utilizados. O processo de identificação dos 
artigos relevantes para a meta-síntese proposta envolveu diversas etapas de seleção, a partir do Portal de Periódicos Capes.

Inicialmente, foram utilizadas as palavras-chave produtiv* E pesquisador, realizandose a busca de apenas artigos publicados nos últimos dez anos. Utilizou-se a palavra produtiv* para que fossem recuperados artigos que tivessem também palavras correlatas, como produtivismo e produtividade, tendo sido encontrados 1.875 documentos indexados. Para refinar a pesquisa, adicionou-se à busca inicial a palavra avaliação (avaliação produtiv* AND pesquisador) e foram selecionados apenas artigos, tendo sido encontrados 41 documentos.

A partir da leitura dos títulos e resumos, foram excluídos 24 artigos, por serem "falsos positivos", ou seja, embora contivessem as palavras avaliação, produtiv* e pesquisador, não estavam relacionados à pesquisa proposta. Dos 17 artigos restantes, a partir da leitura e análise da metodologia empregada, foram eliminados 13 artigos, dentre aqueles cujo foco principal era o levantamento e análise de dados quantitativos (8), artigos de revisão teórica (2) e de pesquisa bibliométrica (3), restando 4 artigos. A tabela detalhada com os dados de cada um dos 41 documentos encontrados e as razões de sua inclusão/exclusão encontra-se disponível em anexo.

De acordo com Hoon (2013), toda síntese deve procurar incluir estudos que apresentem o maior número possível de fontes primárias. Isso foi realizado conforme os critérios de inclusão e exclusão apresentados na tabela 1:

Tabela 1 - Critérios para inclusão ou exclusão

\begin{tabular}{|c|c|c|}
\hline Critério & Comentário & Razões para exclusão \\
\hline Estudos qualitativos & $\begin{array}{l}\text { Em razão de terem sido encontrados poucos } \\
\text { estudos que tratam da forma como o pesquisador } \\
\text { vivencia a avalia a política de avaliação da } \\
\text { CAPES-CNPQ, foram considerados os estudos } \\
\text { qualitativos, sendo esses classificados como } \\
\text { estudos de caso ou não. }\end{array}$ & $\begin{array}{c}\text { Não reportar estudos } \\
\text { qualitativos }\end{array}$ \\
\hline $\begin{array}{c}\text { Estudos plurilíngues, em } \\
\text { que é dada voz ao } \\
\text { pesquisador }\end{array}$ & $\begin{array}{l}\text { Diversos artigos fazem avaliação da produção } \\
\text { acadêmica em função da análise de dados } \\
\text { secundários disponíveis na plataforma Lattes ou } \\
\text { em relatórios da CAPES, mas não consideram a } \\
\text { vivência e a avaliação direta dos pesquisadores. } \\
\text { Considerou-se que, diante do objetivo de } \\
\text { pesquisa, era fundamental que o artigo abarcasse } \\
\text { a voz/discurso do pesquisador (estudos não } \\
\text { monológicos). }\end{array}$ & $\begin{array}{c}\text { Utilizar métodos } \\
\text { quantitativos; considerar } \\
\text { apenas dados referentes à } \\
\text { produção acadêmica para } \\
\text { análise (dados } \\
\text { secundários); estudos } \\
\text { puramente teóricos ou } \\
\text { bibliométricos. }\end{array}$ \\
\hline
\end{tabular}

Fonte: Elaborado pelos autores (2019).

Dos quatro artigos selecionados, um é classificado diretamente pelos autores como sendo estudo de caso e três são estudos qualitativos aprofundados, podendo ser caracterizados 
como estudos de caso, por atenderem aos critérios descritos por Ragin e Becker (1992). Os três situam a escolha do caso/ objeto de estudo, consideram o contexto e as especificidades do mesmo. Como os critérios de inclusão envolveram reportar estudos qualitativos e dar voz ao pesquisador, os quatro artigos foram incluídos na meta-síntese. Diante do reduzido número de artigos que atenderam aos critérios estabelecidos, não foi adotado nenhum critério adicional de inclusão/exclusão.

Em comum, os artigos selecionados para a análise possuem o fato de ter sido dada voz ao pesquisador. Em todos eles, houve espaço para a manifestação do pesquisador, o que, como se observou, tem sido realizado em reduzido número de pesquisas publicadas. A maior parte dos artigos encontrados trabalha com dados secundários, com ênfase sobre a produção acadêmica registrada. Ou seja, essas pesquisas partem dos critérios de avaliação estabelecidos pela Capes/CNPQ para a realização de suas análises, sem que haja prévio questionamento sobre as práticas que essas políticas têm induzido.

Assim, os artigos selecionados, ao trabalhar não a partir dos dados numéricos de publicação, mas a partir da voz, do posicionamento dos sujeitos pesquisadores, possibilitam a problematização das políticas públicas de avaliação de produtividade. Ainda, todos os artigos selecionados referem-se exclusivamente ao contexto brasileiro público de pesquisa e ensino.

Após definidos os artigos que atenderam aos critérios de inclusão na meta-síntese, foram realizados os seguintes procedimentos, conforme Collis e Hussey (2005): i) redução dos dados dos estudos, com vistas à sua categorização e inter-relação; ii) os dados inter-relacionados foram analisados em nível comparativo, buscando influências mútuas; iii) a partir da elaboração de redes causais ou de influência mútua foi realizada a síntese de casos cruzados proposta por Hoon (2013), conforme tabela 2 abaixo, que sintetiza as etapas da meta-síntese adotadas na pesquisa:

Tabela 2 - Protocolo da meta-síntese

\begin{tabular}{|c|c|c|c|}
\hline $\begin{array}{l}\text { Fases da meta- } \\
\text { síntese }\end{array}$ & Objetivo analítico & $\begin{array}{c}\text { Estratégia ou } \\
\text { procedimento analítico } \\
\text { utilizado }\end{array}$ & $\begin{array}{l}\text { Resultados para a geração de } \\
\text { uma contribuição teórica }\end{array}$ \\
\hline $\begin{array}{l}\text { Elaboração da } \\
\text { questão de } \\
\text { pesquisa }\end{array}$ & $\begin{array}{l}\text { Imersão na literatura } \\
\text { referente às políticas } \\
\text { públicas de avaliação do } \\
\text { trabalho do docente- } \\
\text { pesquisador, produção } \\
\text { acadêmica, produtivismo, } \\
\text { capitalismo acadêmico e a } \\
\text { percepção do trabalhador } \\
\text { frente a essas políticas }\end{array}$ & $\begin{array}{l}\text { Especificação a priori a } \\
\text { partir de buscas livres } \\
\text { acerca da relação entre o } \\
\text { pesquisador e as políticas } \\
\text { de avaliação em bases de } \\
\text { dados, periódicos e livros. }\end{array}$ & $\begin{array}{l}\text { Identificação da lacuna teórica e } \\
\text { da pergunta de pesquisa: como os } \\
\text { pesquisadores brasileiros têm } \\
\text { estudado o posicionamento de } \\
\text { seus pares diante da política de } \\
\text { avaliação da produtividade } \\
\text { científica no país formulada pela } \\
\text { CAPES e CNPQ? }\end{array}$ \\
\hline
\end{tabular}




\begin{tabular}{|c|c|c|c|}
\hline $\begin{array}{l}\text { Identificação } \\
\text { de pesquisa } \\
\text { relevante }\end{array}$ & $\begin{array}{c}\text { Pesquisa exaustiva da } \\
\text { literatura disponível com } \\
\text { vistas a não excluir do } \\
\text { estudo informações } \\
\text { relevantes. }\end{array}$ & $\begin{array}{c}\text { Seleção das palavras-chave } \\
\text { adotadas para busca: } \\
\text { avaliação produtiv* AND } \\
\text { pesquisador. }\end{array}$ & $\begin{array}{l}\text { Foram encontrados } 41 \\
\text { documentos. }\end{array}$ \\
\hline $\begin{array}{l}\text { Critérios de } \\
\text { inclusão }\end{array}$ & $\begin{array}{l}\text { Dois critérios de inclusão e } \\
\text { exclusão foram } \\
\text { espeficicados: i) estudos } \\
\text { qualitativos e ii) } \\
\text { plurilíngues, em que fosse } \\
\text { dada voz ao pesquisador } \\
\text { (estudos não monológicos) }\end{array}$ & $\begin{array}{c}\text { Tabulação dos } 41 \text { artigos } \\
\text { encontrados e classificação } \\
\text { em função dos critérios de } \\
\text { inclusão e exclusão } \\
\text { adotados. }\end{array}$ & $\begin{array}{l}\text { Dos } 41 \text { artigos encontrados, } 4 \\
\text { foram incluídos na meta-síntese. }\end{array}$ \\
\hline $\begin{array}{c}\text { Extração e } \\
\text { codificação de } \\
\text { dados }\end{array}$ & $\begin{array}{l}\text { Leitura integral e detalhada } \\
\text { dos artigos selecionados; } \\
\text { codificação das } \\
\text { características e relações } \\
\text { possíveis de serem } \\
\text { estabelecidas com a teoria } \\
\text { em relação à pergunta de } \\
\text { pesquisa } \\
\end{array}$ & $\begin{array}{l}\text { Desenvolvimento de uma } \\
\text { tabela de codificação de } \\
\text { informações e insights } \\
\text { advindos da leitura }\end{array}$ & $\begin{array}{l}\text { Elaboração de considerações } \\
\text { referentes aos contextos de } \\
\text { estudo; tabela de codificação } \\
\text { válida; inter-relação entre } \\
\text { códigos. }\end{array}$ \\
\hline $\begin{array}{l}\text { Análise em } \\
\text { nível de caso } \\
\text { específico }\end{array}$ & $\begin{array}{l}\text { Identificação das relações e } \\
\text { constructos em cada caso } \\
\text { ou estudo que melhor } \\
\text { explicam a relação entre a } \\
\text { percepção da política de } \\
\text { avaliação e o fazer } \\
\text { acadêmico do pesquisador- } \\
\text { docente. } \\
\end{array}$ & $\begin{array}{l}\text { Identificação e } \\
\text { estabelecimento de } \\
\text { relações intra-caso (rede } \\
\text { intra-causal) }\end{array}$ & $\begin{array}{c}\text { Identificação de temas ou } \\
\text { elementos centrais, conceitos, } \\
\text { padrões ou relações em cada caso }\end{array}$ \\
\hline $\begin{array}{l}\text { Síntese em } \\
\text { nível } \\
\text { transversal }\end{array}$ & $\begin{array}{l}\text { Transposição das relações } \\
\text { intra-caso para relações } \\
\text { meta-caso. Acumulação de } \\
\text { elementos constitutivos a } \\
\text { partir do cruzamento dos } \\
\text { casos para a construção de } \\
\text { um padrão geral entre as } \\
\text { variáveis ou elementos } \\
\text { encontrados }\end{array}$ & $\begin{array}{c}\text { Estabelecimento de relações } \\
\text { entre os casos (rede meta- } \\
\text { causal) }\end{array}$ & $\begin{array}{c}\text { Identificação de padrões, } \\
\text { estruturas ou modelos; } \\
\text { categorização e exposição dos } \\
\text { elementos para garantir validade. }\end{array}$ \\
\hline $\begin{array}{l}\text { Construção de } \\
\text { teoria a partir } \\
\text { da meta-síntese }\end{array}$ & $\begin{array}{c}\text { Identificação da } \\
\text { necessidade de articulação } \\
\text { da percepção da política de } \\
\text { produtividade científica à } \\
\text { resposta (o fazer) frente à } \\
\text { política - reconhecimento }\end{array}$ & $\begin{array}{c}\text { Relacionar os resultados } \\
\text { encontrados à literatura da } \\
\text { área; triangulação de dados } \\
\text { e autores; aprofundamento } \\
\text { da literatura acerca das } \\
\text { formas de subjetividade do } \\
\text { pesquisador; identificação } \\
\text { de perguntas-chave e gaps } \\
\text { de pesquisa }\end{array}$ & $\begin{array}{c}\text { Há aspectos subjetivos pouco } \\
\text { esclarecidos pela literatura no que } \\
\text { se refere ao simbolismo e à } \\
\text { motivação do pesquisador para } \\
\text { atender aos critérios de avaliação. } \\
\text { Os estudos encontrados limitam- } \\
\text { se no que se refere à } \\
\text { contextualização histórica, às } \\
\text { vozes de pesquisa, e à } \\
\text { problematização das políticas de } \\
\text { avaliação. } \\
\end{array}$ \\
\hline Discussão & $\begin{array}{l}\text { Discussão dos resultados da } \\
\text { meta-síntese e limitações } \\
\text { identificadas }\end{array}$ & $\begin{array}{l}\text { Discussão sobre rigor, } \\
\text { confiabilidade e validade }\end{array}$ & $\begin{array}{c}\text { Legitimação da validade e } \\
\text { confiabilidade dos procedimentos } \\
\text { utilizados }\end{array}$ \\
\hline
\end{tabular}

Fonte: Elaborado pelos autores (2019). 


\section{Análise dos artigos}

Após o estabelecimento dos critérios elencados na tabela 1 e a seleção dos artigos (conforme tabela 3 abaixo), iniciou-se a análise de cada um dos estudos em nível de caso específico.

Tabela 3 - Artigos selecionados segundo periódico e ano de publicação

\begin{tabular}{l|l|l}
\hline $\begin{array}{c}\text { Autores e ano de } \\
\text { publicação }\end{array}$ & \multicolumn{1}{c|}{ Revista } & \multicolumn{1}{c}{ Título } \\
\hline Oliveira e Mello (2014) & $\begin{array}{l}\text { RBPG. Revista brasileira } \\
\text { de pós-graduação }\end{array}$ & $\begin{array}{l}\text { Indicadores para a avaliação da produtividade em } \\
\text { pesquisa: a opinião dos pesquisadores que concorrem a } \\
\text { bolsas do CNPq na área de Biociências }\end{array}$ \\
\hline Goldani et al. (2010) & $\begin{array}{l}\text { RBPG. Revista brasileira } \\
\text { de pós-graduação }\end{array}$ & $\begin{array}{l}\text { A questão da produção do conhecimento: desafios na } \\
\text { gestão dos programas de pós-graduação }\end{array}$ \\
\hline Serra et al. (2008) & $\begin{array}{l}\text { Revista de } \\
\text { Administração } \\
\text { Mackenzie }\end{array}$ & $\begin{array}{l}\text { Publicar e difícil ou faltam competências? O desafio de } \\
\text { pesquisar e publicar em revistas cientificas na visão de } \\
\text { editores e revisores internacionais }\end{array}$ \\
\hline Alves et al., 2015 & Em Questão & $\begin{array}{l}\text { Fatores que interferem no (não) credenciamento de } \\
\text { pesquisadores em programas de pós-graduação: um } \\
\text { estudo nas universidades públicas em Goiás }\end{array}$ \\
\hline
\end{tabular}

Fonte: Elaborado pelos autores (2019).

A análise em nível de caso específico seguiu o modelo adaptado de Hoon (2013), conforme tabela abaixo, sendo que para cada item de análise foram estabelecidos critérios a serem observados.

Tabela 4 - Análise em nível de caso específico

\begin{tabular}{c|l}
\hline Itens de ANÁLISE & \multicolumn{1}{c}{ Itens OBSERVADOS } \\
\hline Identificação do artigo & Autores, filiação, periódico de publicação, tipo de estudo \\
\hline Objetivos & Questão de pesquisa, objetivos, possíveis contribuições do estudo/ justificativa \\
\hline Referencial teórico & Quais os pressupostos, conceitos principais adotados, embasamento teórico \\
\hline Contextualização & Onde o estudo foi realizado, informações sobre o local, contexto, área \\
\hline Metodologia & $\begin{array}{l}\text { Desenho de pesquisa, unidade de análise, número de casos, grupos ou pessoas } \\
\text { abordadas, técnicas de coleta e análise de dados, critérios de validade adotados }\end{array}$ \\
\hline $\begin{array}{c}\text { Interpretação - Análise de } \\
\text { dados e insights }\end{array}$ & $\begin{array}{l}\text { Como os dados são analisados, quais são as contribuições teóricas encontradas, } \\
\text { quais os modelos e constructos apresentados }\end{array}$ \\
\hline Discussão & $\begin{array}{l}\text { Contribuições para o avanço da teoria acerca da percepção da política pública e } \\
\text { significação de si mesmo (fomas de subjetivação) na academia; limitações e } \\
\text { contribuições do estudo }\end{array}$ \\
\hline Avaliação geral & $\begin{array}{l}\text { Análise da relevância do estudo para a questão de pesquisa; análise da validade e } \\
\text { confiabilidade }\end{array}$ \\
\hline
\end{tabular}

Fonte: Adaptado pelos autores a partir de Hoon (2013). 
Adicionalmente, procedeu-se à classificação dos artigos selecionados em função de critérios de impacto e avaliação das revistas em que foram publicados. Percebeu-se que os artigos que tratam dessa temática não estão entre os mais citados e que as revistas que publicam esse tipo de pesquisa também não estão entre as mais bem classificadas (nenhuma com avaliação "A"). Seria o tema de pesquisa muito novo ou ainda não considerado relevante? Ou faltaria melhor detalhamento e rigor metodológico para que essas publicações fossem vinculadas em revistas de maior impacto? Ou foi escolha deliberada dos autores?

Após intensa busca por outras publicações referentes ao tema, efetuado por meio de combinações aleatórias de palavras-chave vinculadas à pergunta de pesquisa e que atendessem aos critérios previamente determinados, foi identificado um artigo publicado na revista Brazilian Journal of Medical and Biological Research, classificado como A2 em Psicologia, mas como B4 em Biologia, e sem avaliação em Administração, com o título: "The growing competition in Brazilian science: rites of passage, stress and burnout”.

Ainda assim, trata-se de publicação nacional. Não foram encontradas publicações em revistas internacionais sobre a percepção da avaliação a partir do pesquisador brasileiro. Tecemos algumas hipóteses: i) por se tratar de autores críticos, há maior preocupação na apresentação dos resultados da pesquisa no cenário nacional; ii) estudos qualitativos que trabalham com múltiplas vozes possuem espaço restrito de publicação nas revistas internacionais; iii) em se tratando de um tema notadamente nacional, não estão sendo realizadas análises que vão além do contexto local e que possam levar a reflexões sobre como o fenômeno tem acontecido no exterior; iv) os resultados têm sido expostos sem que haja proposição e construções teóricas, o que torna os estudos circunstanciais e excessivamente empíricos; v) o tema é novo e exige aprofundamento teórico e maiores pesquisas. De toda forma, surge como fundamental a proposição de teorias a partir do tema de estudo, que ultrapassem o entendimento do objeto em sua forma fenomênica, ou seja, na forma como se apresenta.

Para a realização de síntese em nível transversal, Hoon (2013) sugere a classificação dos artigos segundo o nível de contribuição em diversos aspectos. Segundo a autora, essa classificação permite analisar o quanto os estudos são relacionados ou dissonantes por meio de sua comparação e contrastes.

Foram elaborados pelas pesquisadoras cinco critérios de comparação e análise. Os critérios criados partem da filosofia de linguagem de Bakhtin $(2011$; 2012), em que, pela teoria de leitura nele inspirada, podem se fazer ouvir múltiplas vozes num texto - plurilinguismo - ou apenas uma voz - monologismo (quando se opera com o discurso oficial, que se quer fazer único e verdadeiro). Os conceitos de dialogismo e historicidade de Bakhtin, por sua vez, 
remetem à dimensão ética, à responsividade, ao posicionamento ativo/ responsivo, em que se faz ouvir a posição do autor. Para Bakhtin, o sujeito não pode abster de posicionar-se na arena de vozes, ainda que a aparente abstenção seja o seu próprio posicionamento. Seguem os critérios adotados:

i) nível de criticidade do estudo (alto, médio, baixo): refere-se ao posicionamento crítico dos autores face às políticas de avaliação; envolve o grau de (não) naturalização incluída no estudo.

ii) grau de plurilinguismo (alto, médio, baixo). Nesse aspecto cabe destacar que os estudos monológicos (que são maioria), ou seja, estudos em que os pesquisadores não foram ouvidos, não entraram para a meta-síntese, sendo que esse foi um dos critérios de inclusão dos artigos a serem analisados;

iii) grau de explicitação do posicionamento político/ideológico dos autores (alto, médio, baixo);

iv) qualidade dos insights e contribuição para a compreensão do fenômeno/ questão de pesquisa (alto, médio, baixo).

v) nível de contextualização sócio-histórica/ historicidade contemplada no estudo

Procedeu-se, portanto, à análise dos artigos por meio das categorias supra explicitadas. Cabe destacar que esses critérios não se referem, em absoluto, à qualidade dos artigos analisados, mas ao seu potencial contributivo para a sustentação de contribuição teórica, construção de teoria e relações necessárias à pergunta de pesquisa formulada na pesquisa em questão. Ressalta-se que cada um dos artigos selecionados foi escrito com vistas ao alcance de objetivos específicos, que não coincidem com o desta meta-síntese.

\section{Discussão e resultados}

Observou-se, com o restrito número de artigos encontrados em que fosse dada voz ao pesquisador, que as pesquisas sobre sua produtividade têm sido feitas sem que os próprios pesquisadores sejam ouvidos. Diversos trabalhos realizam suas análises a partir dos resultados quantitativos apresentados pelos pesquisadores estudados (ex: análise de currículos e número de artigos publicados). Constatou-se que o processo de produção científica, a subjetividade envolvida, a consciência, e as reflexões e o posicionamento do pesquisador sobre o seu fazer não tem sido suficientemente explorados.

Dentre os trabalhos em que é dada (alguma) voz ao pesquisador, verificou-se que:

i) Trabalha-se prioritariamente com questionários e com a lógica de mensuração, sendo apresentadas questões fechadas para preenchimento. Em alguns casos é apresentada uma única questão aberta, também bastante direcionada. Ou seja, o espaço para que o 
pesquisador exponha o seu ponto de vista e a sua vivência com os processos avaliativos tem sido bastante restrito nas pesquisas nacionais identificadas;

ii) Há limitada apropriação histórica e contextual do fenômeno. Ou seja, embora seja frequentemente realizada uma exposição introdutória que abarque aspectos históricos das políticas de avaliação da pós-graduação no país, a análise dos dados e resultados tem sido feita descolada do contexto histórico. A história aparece como um item a ser preenchido tecnicamente, sem que seja tomada em sua dimensão de propiciar uma análise aprofundada e de fato contextualizada.

iii) Por sua vez, a insuficiente apropriação de aspectos históricos nas análises parece autorizar os autores a partir de pressupostos questionáveis e por vezes naturalizados. Por exemplo, um dos artigos analisados busca identificar quais novos critérios poderiam ser agregados ao sistema de avaliação, tomando a avaliação como um processo natural(izado);

iv) Os estudos envolvem áreas específicas: biociências, medicina pediátrica, administração. Apenas uma pesquisa trabalhou com docentes de mais de uma área, no estado de Goiás. Nesse caso, trabalhou-se prioritariamente com questionários.

v) Em nenhum dos artigos encontrados de fato houve um questionamento ou problematização sobre o porquê de se avaliar, sobre quem tem legitimidade para avaliar, o que significa a avaliação, para que e para quem se avalia, qual o significado que a avaliação possui para os pesquisadores, ou como esses docentes se veem e vivenciam a relação de avaliação - o que causou surpresa à pesquisadora.

Outro achado importante é o de que a política de avaliação não apenas avalia, mas fortalece e induz determinadas práticas de pesquisa. Por exemplo, um dos artigos sugere que se faça mais pesquisa quantitativa para incremento no número de publicações, já que esse tipo de publicação costuma apresentar maior índice de aceitação nos periódicos indexados. Esse posicionamento, expresso no artigo, parece aproximar-se de certa naturalização dos fenômenos; os autores abstêm-se de posicionar-se criticamente, de considerar os cientistas como um grupo ativo, que é capaz de alterar a sua realidade social. Cabe ressaltar que o artigo em questão deu voz aos "especialistas", ou seja, representa um grupo cientistas. Ao se não problematizar o contexto e as vozes, corre-se o risco de se adotar posicionamentos funcionalistas, que legitimam enunciados já em evidência, naturalizando-se a realidade e comprometendo-se a visão do sujeito como agente de transformação.

Segundo Carvalho et al. (2013), pesquisadores da sociologia brasileira encontram maneiras de se manter dentro do sistema, sem estarem produzindo de acordo com os seus critérios. A conclusão dos autores aponta que "parece haver, portanto, outros critérios de uma ordem mais subjetiva que sustenta, inclusive, todo o simbolismo desse sistema de avaliação da produção científica". 
Borsoi e Pereira (2013) verificaram que "mais de um terço dos integrantes da pesquisa afirma não se sentir produtivo, apesar de trabalhar muito. Poucos são aqueles que se deram conta de que são produtivos, mesmo não conseguindo cumprir as metas de publicação definidas pelos programas de pós-graduação e pela Capes” (BORSOI; PEREIRA, 2013, p. 1220). O foco na formação de alunos, na preparação das aulas, é desvalorizado mediante a imperiosa necessidade de publicação das pesquisas realizadas. Os autores verificaram também que existe maior índice de busca por auxílio médico e/ou psicológico entre as docentes mulheres. Outro achado interessante é de que os pesquisadores "precisaram chegar ao limite do que podiam suportar em termos de sofrimento, e até de adoecimento, para perceberem que era necessário modificar sua relação com o trabalho" (p. 1219). Seria esse um achado exclusivo dos profissionais docentes? Quais as particularidades dessa relação e no que ela se aproxima de outras situações de trabalho? Qual a relevância da formação dos mestrandos e doutorandos enquanto futuros professores nesta perspectiva?

O simbolismo presente no sistema de avaliação da produção científica parece apresentar relação com a significativa dedicação dos pesquisadores ao trabalho e sua constante percepção de improdutividade, aliada à dificuldade de se modificar essa relação com o trabalho. Em outras palavras, por que, apesar de trabalhar muito, o pesquisador se sente improdutivo? Por que é apenas quando chega no limite em termos de sofrimento e adoecimento que o pesquisador percebe a necessidade de modificar sua relação com o trabalho? Como esta realidade está afetando a cada um de nós?

Constatou-se também que muitos artigos abordam a questão do sofrimento no trabalho acadêmico de forma genérica, sem refinar ou delimitar a relação do pesquisador com as políticas de avaliação. Ora, parte desse sofrimento poderia estar relacionado à forma como se é avaliado, como o sujeito avalia a si próprio?

Essa meta-síntese aponta que há aspectos subjetivos pouco esclarecidos pela literatura no que se refere ao simbolismo e a motivação do pesquisador para atender aos critérios de avaliação. Percebe-se que há, sim, um envolvimento significativo do pesquisador com o seu trabalho. Mas, qual a relação das políticas de avaliação com o fazer do pesquisador? Essa pergunta é, acreditamos, o próprio pesquisador quem deve investigar para responder.

Conforme aponta Faria (2017, p. 404), "como pensar uma forma de reconhecimento que não implique o sequestro da subjetividade? Como pensar um reconhecimento que não seja ou que não implique uma forma de submetimento a critérios de reconhecimento da classe dominante? Diversos estudos (FARIA, HOPFER, 2006) têm relacionado a avaliação a formas de controle. 
Quais são as implicações subjetivas que as práticas avaliativas engendram? Segundo Faria (2017, p. 383): "Para Hegel, subjetividade e intersubjetividade são indissociáveis, pois a identidade de um ser-em-si (de um sujeito) se constitui em sua relação com um ser-outro (Outro), diferente dele". E prossegue: "Portanto, o reconhecimento das diferenças é um reconhecimento mútuo e é nele que se inscreve a constituição da subjetividade, a qual é condição da relação intersubjetiva. Tal é a dialética da alteridade” (FARIA, 2017, p. 383).

Evidenciou-se que a visão do pesquisador sobre sua própria (im)produtividade parte de critérios externos, que ele próprio legitima ao buscar alcança-los, passando a constituir a sua própria subjetividade a partir desses critérios. Portanto, estudos que possuem como objeto as políticas de avaliação devem considerar os modos de construção da subjetividade do pesquisador.

\section{Conclusões}

Esta meta-síntese abordou um tema recente na história das universidades brasileiras e pouco explorado na literatura. Buscou-se construir teorias e reflexões novas acerca do problema identificado por meio dos critérios apresentados por Hoon (2013).

Como limitações do estudo, pode-se citar:

i) a meta-síntese foi realizada com pesquisas qualitativas, conforme proposta de Hoon (2013);

ii) os artigos/ estudos de caso a partir dos quais foi elaborada essa meta-síntese não se referem a uma mesma área científica. Para minimizar os efeitos, os artigos foram analisados dentro de seu contexto, propósitos e objetivos específicos;

iii) os trabalhos foram explorados a partir de uma determinada epistemologia, que considera fundamental o caráter sócio-histórico e a capacidade de posicionamento dos indivíduos, assim como o raciocínio crítico e a expressão direta dos sujeitos, sem que sujeitos emudecidos sejam falados por outros.

Verificou-se que os estudos publicados na área, com algumas exceções: restringem o espaço de enunciação do pesquisador, seja por não considerar o pesquisador ou por trabalhar com modelos fechados de avaliação; limitam-se no que se refere à apropriação da história e do contexto como forças de análise dos dados; partem de pressupostos que naturalizam a avaliação e, portanto, restringem a problematização do fenômeno.

Em relação à avaliação, a discussão deve centrar-se sobre critérios mais justos e igualitários ou questionar a própria necessidade da avaliação, discurso esse hegemônico e naturalizado? Quais são os pressupostos não imediatamente visíveis quando se defende que o trabalho de uns deve ser avaliado por outros? Qual a legitimidade de uma avaliação de um sujeito sobre o trabalho de outro sujeito? Os critérios de avaliação podem ser definidos por 
pessoas diferentes daquelas que estão sendo avaliadas? Por que, afinal, se avalia? Quais as contradições envolvidas e vivenciadas no processo? Para além do julgamento da relevância da avaliação, cabe ainda uma reflexão sobre o seu processo, pertinência, resultados e procedimentos.

Com os resultados desse estudo, busca-se encorajar pesquisas na área que considerem a voz dos pesquisadores, que se apropriem e contextualizem historicamente as recentes políticas de avaliação da pós-graduação no país, e que de fato problematizem a relação de avaliação, de modo crítico, politizado e situado, considerando o sujeito sócio-histórico como posicionado e produtor de mudanças e reflexões. Dessa maneira, será possível trazer novos elementos para a análise da relação do pesquisador com a avaliação, relação essa contraditória e múltipla e que exige substantivo investimento objetivo e subjetivo do pesquisador, inserindo-se a questão no debate científico, para que possa ser vista e pesquisada de maneira sistemática.

\section{Referências}

ALVES, Itala Moreira et al. Fatores que interferem no (não) credenciamento de pesquisadores em programas de pós-graduação: um estudo nas universidades públicas em Goiás. Em Questão, Porto Alegre, v. 21, n. 1, jan./abr. 2015.

BAKHTIN, Mikhail. Estética da criação verbal. São Paulo: Martins Fontes, 2011.

BAKHTIN, Mikhail. A filosofia do ato responsável. São Paulo: Ed. Pedro e João, 2012.

BERNARDO, Marcia Hespanhol. Produtivismo e precariedade subjetiva na universidade pública: o desgaste mental dos docentes. Psicologia \& Sociedade, Recife, v. 26, p. 129-39, 2014. Disponível em: http://www.scielo.br/scielo.php?script=sci_arttext\&pid=S010271822014000500014\&lng=en\&nrm=iso. Acesso em: 16 jan. 2017.

BERTONHA, João Fábio. Produção e produtividade no meio acadêmico. A "ditadura do Lattes” e a Universidade contemporânea. Revista Espaço Acadêmico, Maringá, n. 100, 2009.

BORSOI, Izabel Cristina Ferreira; PEREIRA, Flavilio Silva. Professores do ensino público superior: produtividade, produtivismo e adoecimento. Universitas Psychologica, Bogotá, v. 12, n. 4, p. 1211-1233, 2013.

BRASIL. Parecer no 977/65. Brasília, 1965. Disponível em: https://www.gov.br/capes/ptbr/centrais-de-conteudo/parecer-cesu-977-1965-pdf/view. Acesso em: 28 dez. 2016.

CARVALHO, Kátia et al. Aspectos gerenciais da política científica brasileira: um olhar sobre a produção científica do campo da sociologia face aos critérios de avaliação do CNPq e da CAPES. Em Questão, Porto Alegre, v. 19, n. 1, p. 187-212, jan./jun. 2013.

CASTIEL, Luis David et al. Entre fetichismo e sobrevivência: o artigo científico é uma mercadoria acadêmica? Cad. Saúde Pública, Rio de Janeiro, v. 23, n. 12, p. 30413050, 2007.

CHAUÍ, Marilena. A universidade pública sob nova perspectiva. Rev. Bras. Educ., Rio de Janeiro, n. 24, p. 5-15, 2003. 
COLLIS, Jill; HUSSEY, Roger. Pesquisa em administração: um guia prático para alunos de graduação e pós-graduação. 2. ed. Porto Alegre: Bookman, 2005.

FARIA, José Henrique de. Poder, controle e gestão. Curitiba: Juruá, 2017.

FARIA, José Henrique de; HOPFER, Kátia Regina. Controle por resultados no local de trabalho: dissonâncias entre o prescrito e o real. RAE electron., São Paulo, v. 5, n. 1, 2006.

GOLDANI, Marcelo Zubaran et al. A questão da produção do conhecimento: desafios na gestão dos programas de pós-graduação. Revista brasileira de pós-graduação, Brasília, v. 7 , n. 12, 2010.

HANAFI, Sari. University systems in the Arab East: Publish globally and perish locally vs publish locally and perish globally. Current Sociology, American University of Beirut, Líbano, 2011, v. 59, n. 3, p. 291-309.

HOON, Christina. Meta-synthesis of qualitative case studies: an approach to theory building. Organization research methods, Thousand Oaks, California, v. 16, n. 4, p. 522-556, 2013.

LAWRENCE, Peter A. The politics of publication. Nature, California, n. 422, p. 259-261, 2003.

MACHADO, Jardel; PAN, Miriam Aparecida. Do nada ao tudo: políticas públicas e a educação especial brasileira. Educ. Real, Porto Alegre, v. 37, n. 1, p. 273-294, jan./abr. 2012.

MEIS, Leopoldo et al. The growing competition in Brazilian science: rites of passage, stress and burnout. Braz J Med Biol Res, Ribeirão Preto, v. 36, n. 9, p. 1135-1141, 2003.

NUNES, Alexandre; NUNES, Waldete. Considerações sobre o aumento da produtividade do trabalho e suas consequências para os professores e demais trabalhadores do funcionalismo público. REDD - Revista Espaço de Diálogo e Desconexão, Araraquara, v. 6, n. 2, jan. /jun. 2013.

OLIVEIRA, Alexandre Rodrigues; MELLO, Carlos Fernando de. Indicadores para a avaliação da produtividade em pesquisa: a opinião dos pesquisadores que concorrem a bolsas do CNPq na área de Biociências. Revista brasileira de pós-graduação, Brasília, v.11, n. 25, 2014.

PEDRINI, Alexandre de Gusmão. O cientista brasileiro é avaliado? São Carlos: Rima, 2005.

RAGIN, Charles; BECKER, Howard (ed.). What is A Case? Exploring the Foundation of Social Inquiry. Cambridge: Cambridge University Press, 1992.

SERRA, Fernando et al. Publicar e difícil ou faltam competências? O desafio de pesquisar e publicar em revistas cientificas na visão de editores e revisores internacionais. Revista de Administração Mackenzie, São Paulo, v. 9, n. 4, 2008.

SIMÕES, Regina Helena Silva. Da avaliação da educação à educação da avaliação: o lugar do(a) educador(a) no processo da avaliação da pós-graduação no Brasil. Psicologia \&

Sociedade, Recife, v. 16, n.1, p. 124-134, 2004. Disponível em: https://www.scielo.br/j/psoc/a/THdjLwTv5Ln78vcwyfCgqBS/?lang=pt

TRAGTENBERG, Maurício. Sobre educação, política e sindicalismo. 2. ed. São Paulo: Editores Associados; Cortez, 1990. 